
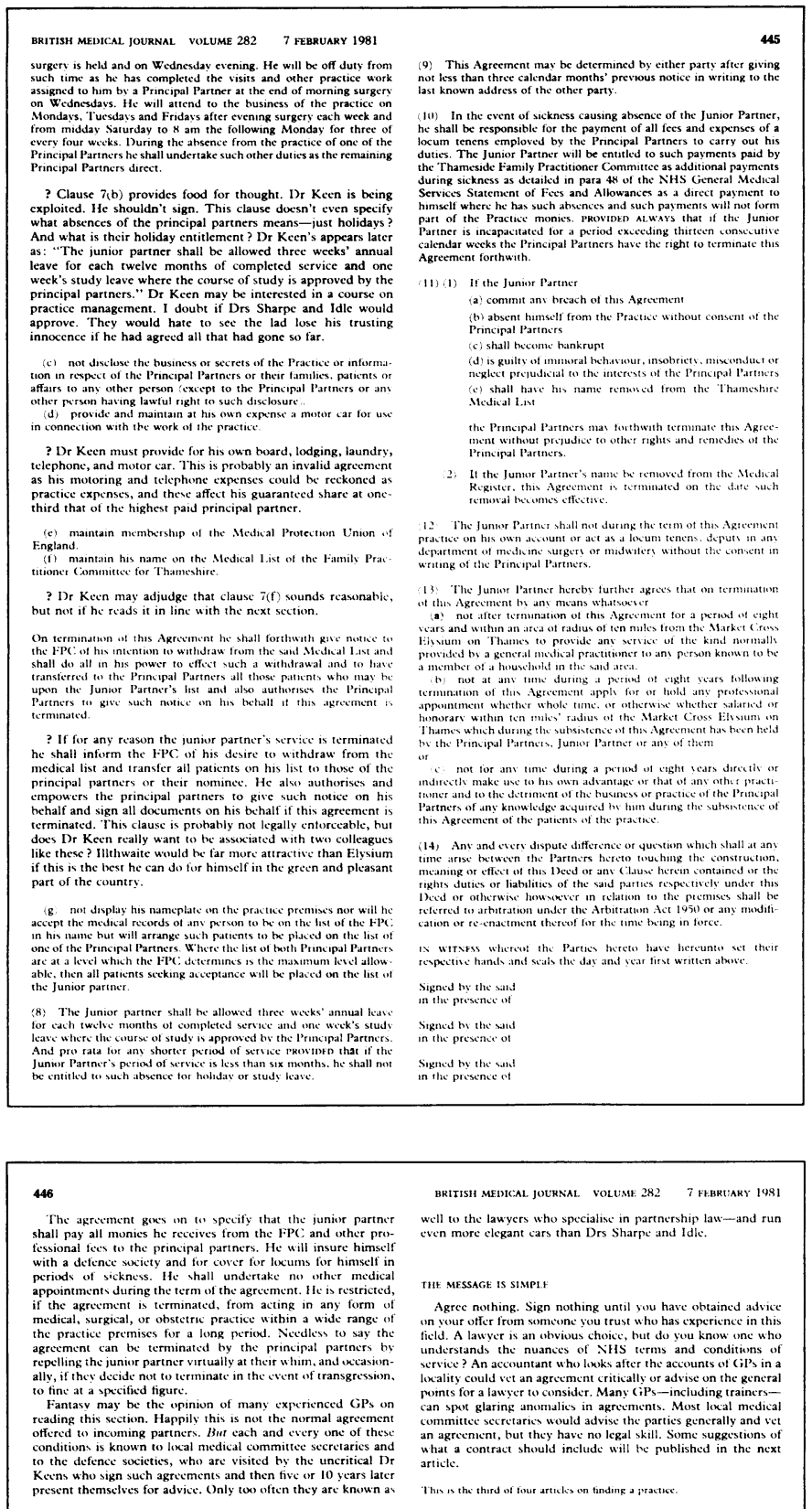

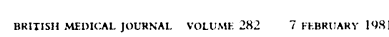
well to the lauycrs who specialise in partnership law--and run
cven more elegant cars than Drs Sharpe and ldice. THE MESSAGE IS SIMPLI

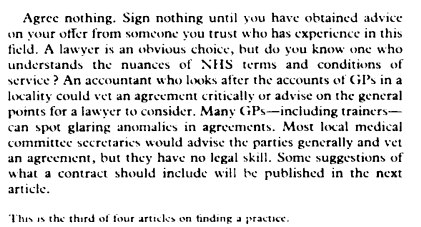

\section{Beyond the Surgery}

\section{General practitioner and the World Health Organisation}

B J ESSEX

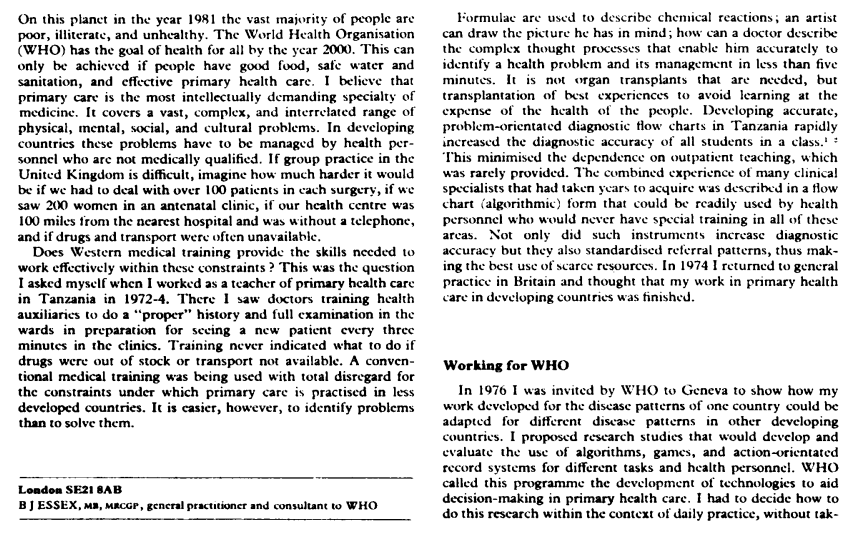

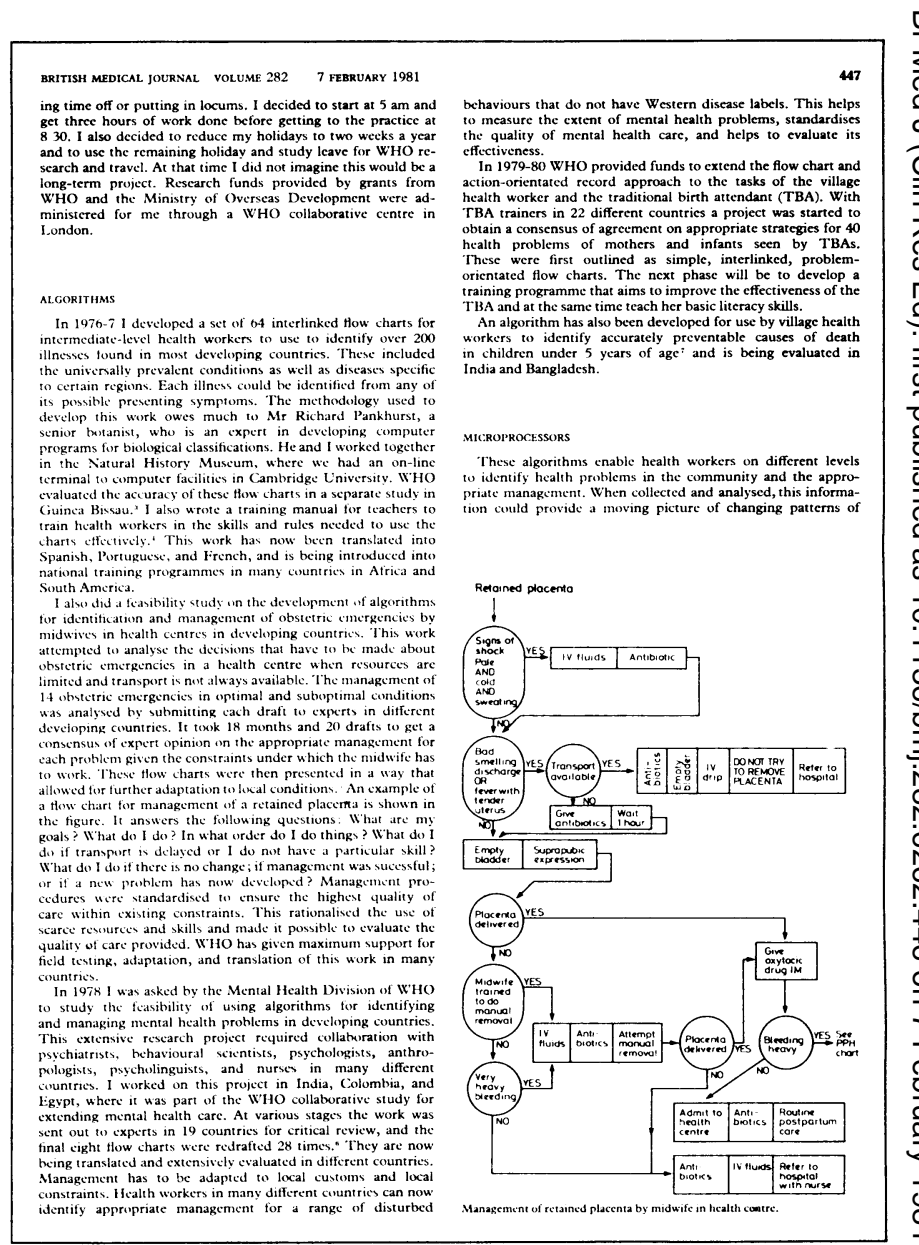

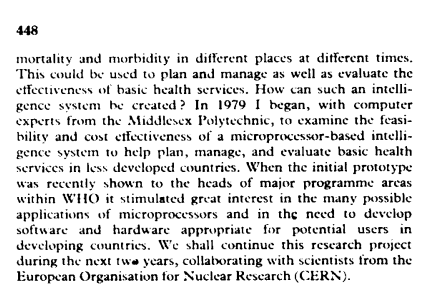

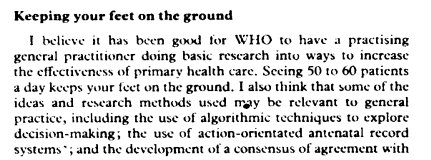

BRTIISH MEDICAI. JOURNAL VOLUME $282 \quad 7$ FEBRUARY 1981 experts on how health workers outside hospitals should manage
and evaluate many kinds of problems.

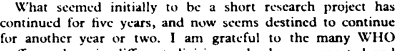

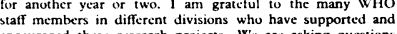

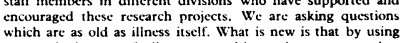

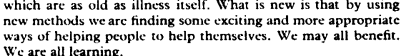
References

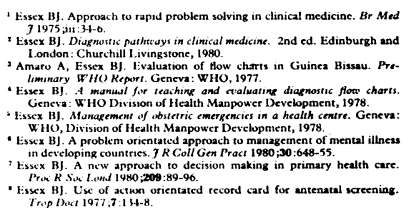

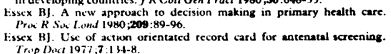
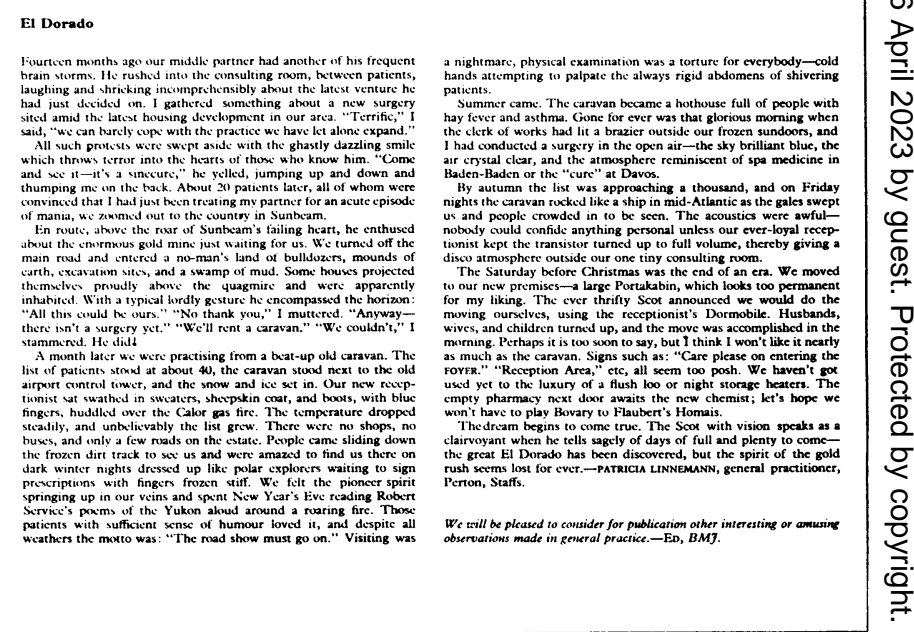